\title{
EFFECT OF SOME AGRO-INDUSTRIAL RESIDUES ON MYCELIAL GROWTH AND PRODUCTION OF LIGNOCELLULOLYTIC ENZYMES BY A FUNGUS NATIVE TO ALGERIAN FOREST
}

\author{
NABILA BELHAMICHE, ${ }^{*}$ FRANCIS DUCHIRON** and SAID BENALLAOUA* \\ *Laboratoire de Microbiologie Appliquée, Faculté des Sciences de la Nature et de la Vie, \\ Université de Bejaia, 06000, Bejaia, Algérie \\ ***Laboratoire de Microbiologie Industrielle, UMR FARE 614 INRA, UFR Sciences Exactes et Naturelles, \\ Université Reims Champagne-Ardenne, Moulin de la Housse, CP 51687 Reims, France \\ Corresponding author: N. Belhamiche, nabila.belhamiche@univ-bejaia.dz
}

Received June 13, 2021

\begin{abstract}
Valorization of agricultural and agro-food by-products by fermentation constitutes a very interesting biotechnological approach for the production of lignocellulolytic enzymes. This work was carried out to reveal the effect of some lignocellulosic materials on the mycelial growth and lignocellulolytic enzymes production by Bjerkandera adusta BRFM 1916. The strain showed ABTS- and guaiacol-oxidation activities. The optimal temperature for mycelial growth was $28{ }^{\circ} \mathrm{C}$. The maximum growth rate of this fungus was achieved on wheat bran $\left(2.08 \pm 0.05 \mathrm{~cm} \mathrm{day}^{-1}\right)$, followed by barley bran, with a significant reduction of $6.73 \%$. Several agricultural lignocellulosic residues were used as substrates for enzymes production. All the data indicated differential utilization of the various materials by the fungus. The selected fungus produced good CMCase $\left(690 \pm 0.066 \mathrm{UL}^{-1}\right)$ and $\beta$-Glu $\left(253 \mathrm{UL}^{-1}\right)$ activities on wheat bran and orange peels, respectively. A high level of $\mathrm{MnP}$ activity $\left(449.21 \pm 3.44 \mathrm{UL}^{-1}\right)$ was obtained on wheat bran.
\end{abstract}

Keywords: Bjerkandera adusta BRFM 1916, enzymes, fungus, growth, lignocellulosic by-products, valorization

\section{INTRODUCTION}

Lignocellulose, the major component of biomass, is the most abundant renewable organic resource on the earth. It is composed mainly of the polysaccharidic polymers, cellulose and hemicelluloses, and the polyphenolic polymer lignin. ${ }^{1}$ Cellulose is constituted entirely by glucan chains linked by $\beta(1 \rightarrow 4)$ bonds, which interact with each other via hydrogen bonds. On the other hand, hemicellulose is a heterogeneous polymer, usually composed of five different sugars (Larabinose, D-galactose, D-glucose, D-mannose, and D-xylose) and some organic acids (acetic and glucuronic acids, among others). The structure of the hemicelluloses is linear and branched. The backbone of the hemicelluloses chain can be formed by repeated units of the same sugar (homopolymer) or by a mixture of different sugars. ${ }^{2}$ The lignin structure is formed by phenylpropane units linked in a large and very complex three-dimensional structure. Three phenyl propionic alcohols are usually found as monomers of lignin, which include the alcohols $p$ coumaryl, coniferyl, and sinapyl. The proportion in which they are present in lignin varies widely depending on the type of the plant. ${ }^{3}$ Lignin acts as a barrier for any solutions or enzymes by linking to both hemicelluloses and cellulose, and preventing the penetration of lignocellulolytic enzymes to the interior of the lignocellulosic structure. Not surprisingly, lignin is the most recalcitrant to degradation component of the lignocellulosic material. ${ }^{4}$ Environmental pollution, one of the major concerns of every government, has increased in developing countries, where a large portion of different byproducts, such as agricultural residues, are considered as waste. This situation stems from the accumulation of large quantities of lignocellulosic by-products, which result from various industries, including the food, pulp and paper, forestry,

Cellulose Chem. Technol., 55 (9-10), 1061-1069(2021) 
agriculture and timber sectors, and, most often, from the lack of their valorization. ${ }^{5}$

The degradation of lignocellulose requires a complex set of extracellular enzymes. Extracellular hydrolases and oxidoreductases are involved in the breakdown of lignocellulose and are produced by many known ligninolytic fungi. The demand for these enzymes has increased in the recent years due to their potential applications in diverse biotechnological areas. Lignocellulosedegrading enzymes are widely used in pollution abatement, especially in the treatment of industrial effluents that contain hazardous compounds, such as dyes, phenols and other xenobiotics. These enzymes also find application in fuel, food, textile, animal feed, paper and pulp industries. However, the ever-increasing demand for these enzymes in the industrial sectors imposes the need for their production from inexpensive raw materials. ${ }^{6,7}$ Because lignocelluloses-based agricultural wastes contain lignin, cellulose and hemicelluloses, which are rich in sugars, these wastes can be utilized as support substrates. Bioconversion of lignocellulosic agro-industrial residues to ligninolytic enzymes constitutes a very interesting biotechnological approach for the production of enzymes, when considering the demand for these enzymes on the global market. ${ }^{8,9}$ While this approach can contribute to the production of several value-added products, it can also help to avoid economic loss and environmental pollution. $^{10,11}$

The current trend in biotechnology research is oriented towards the use of agricultural residues for the production of enzymes and other metabolites, and great success has been attained by many researchers in this regard, mostly using solid-state fermentation technology. ${ }^{12}$ The microorganisms producing these enzymes grown in solid medium are, in most cases, filamentous fungi. Indeed, these environments are similar to their natural environments and their form of vegetative development consisting of branched aerial hyphae is conducive to the colonization of porous solid matrices. In addition, fungi can develop at moisture levels as low as $12 \%$ and support high osmotic pressures, characteristics that yeasts and bacteria generally do not exhibit.

The aim of this work was to evaluate the effect of some lignocellulosic by-products (wheat bran, wheat straw, olive cake, miscanthus, grape pulp, barley bran, and orange peels) as natural abundantly available and low-cost substrates, on the growth of and the production of ligninocellulolytic enzymes by a locally isolated basidiomycete Bjerkandera adusta BRFM 1916.

\section{EXPERIMENTAL \\ Microorganism}

Bjerkandera adusta, a white rot-fungus from the group of basidiomycetes, isolated in Yakourene Forest (Tizi-Ouzou, Algeria) from decayed wood, was used in this study. This basidiomycete was deposited in Centre International de Ressources Microbiennes Champignons Filamenteux (CIRM-CF, INRA/AMU, Marseille, http://www6.inra.fr/cirm_eng/), with accession number BRFM 1916. It was maintained on PDA (Potato Dextrose Agar) medium.

\section{Screening for ligninolytic enzymes production}

Special indicators have been used on the solid media with the purpose of proving the production of lignin-modifying enzymes by the fungus. Screening methods were used for ABTS oxidation and guaiacol oxidation, respectively. ${ }^{13,14}$ The screening was carried on $90 \mathrm{~mm}$ diameter Petri dishes. A single agar disc (1 $\mathrm{cm}$ in diameter) containing mycelial culture was taken from the leading edge and inoculated on the selected media. The plates were incubated at $28{ }^{\circ} \mathrm{C}$ in the dark and were observed daily. Colonies on ABTS medium that showed a green halo were considered as having ABTS-oxidizing activity. ${ }^{15}$ With guaiacol, the appearance of an intense brown colour under and around the fungal colony was considered as a positive reaction resulting from guaiacol oxidation. ${ }^{16}$

\section{Effect of temperature on mycelial growth}

For studying the effect of temperature $\left(20^{\circ} \mathrm{C}, 25\right.$ ${ }^{\circ} \mathrm{C}, 28{ }^{\circ} \mathrm{C}, 30^{\circ} \mathrm{C}, 35{ }^{\circ} \mathrm{C}$ ) on mycelial growth, the culture was carried out on PDA. Data, in terms of colony diameter $(\mathrm{cm})$, were recorded daily.

\section{Effect of different lignocellulosic residues on fungal growth and enzymes production}

To ensure that the fungi used the lignocellulosic materials as the sole carbon source, the fungus was grown and propagated on PDA medium at $28^{\circ} \mathrm{C}$ until mycelia had filled the Petri dish. A passage was then performed with $1 \mathrm{~cm}^{2}$ inoculum placed in the center of another Petri dish containing a modified mineral base medium to deprive the fungus of a carbon source. ${ }^{17}$ For the experimental cultures, $1 \mathrm{~cm}^{2}$ squares taken from the mineral base medium were placed in the center of a plate containing mineral base medium, plus $2 \%$ powdered lignocellulosic materials (wheat bran, wheat straw, olive cake, miscanthus, grape pulp, barley bran, and orange peels) as the sole carbon source. The substrates were pulverized in a coffee grinder until a homogeneous powder was observed (with maximum and minimum particle sizes of 3 and $0.5 \mathrm{~mm}$, respectively). The plates were incubated at $28{ }^{\circ} \mathrm{C}$ until 
mycelia had filled the Petri dish. Growth was followed, in triplicate, taking daily measurements for each substrate, until the mycelium reached the edge of the Petri dish (90 $\mathrm{mm}$ diameter). Mycelial diameter was plotted against time, and growth velocities $(\mu)$ were determined calculating the slope of the growth curve $\left(\mathrm{cm} \mathrm{day}^{-1}\right)$.

\section{Enzymatic assays}

Enzymatic activity was tested from the supernatant obtained from the solid cultures. The agar medium was cut into pieces for collection from the Petri dishes and placed in a $50 \mathrm{~mL}$ centrifuge tube. After centrifugation at $10,000 \mathrm{x} \mathrm{g}$ for $30 \mathrm{~min}$ at $4{ }^{\circ} \mathrm{C}$, the supernatants were clarified by filtration through $0.45 \mu \mathrm{M}$ filters (Millipore). ${ }^{18}$ Endoglucanase activity (CMCase) was measured as described by Ghose. ${ }^{19}$ Reducing sugars were measured by the dinitrosalicylic acid method using D-glucose as a standard. ${ }^{20} \beta$-Glucosidase activity $(\beta$ Glu) was assessed as described by Norkrans. ${ }^{21}$ Laccase activity (Lac) was determined spectrophotometrically according to the method of Lomascolo et al. ${ }^{22}$ Manganese peroxidase (MnP) activity was assayed according to the method of Paszczynski et al. ${ }^{23}$ Lignin peroxydase $(\mathrm{LiP})$ was performed by the method of Tien and Kirk. ${ }^{24}$ Enzymatic activity of $1 \mathrm{U}$ was defined as the amount of enzyme that transforms $1 \mu \mathrm{Mol}$ substrate/min

\section{Statistical analysis}

All the experiments were repeated three times and data were statistically analyzed using one-way ANOVA. Differences among treatments were determined using the test for the least significant differences (LSD) at a significant level $(p<0.05)$. Data are presented as means \pm standard errors (SE).

\section{RESULTS AND DISCUSSION}

Ligninolytic enzymes screening

ABTS oxidizing activity on the plate yielded positive results for Bjerkandera adusta BRFM1916. It was observed that the strain exhibited the dark green ABTS cation radicals during the first day of incubation and that the green halo diameter exceeded the colony diameter (Fig. 1A). As for the guaiacol reaction, the results showed a halo of intense brown color was formed under and around the fungal colony, indicating the presence of ligninolytic enzymes (Fig. 1B).
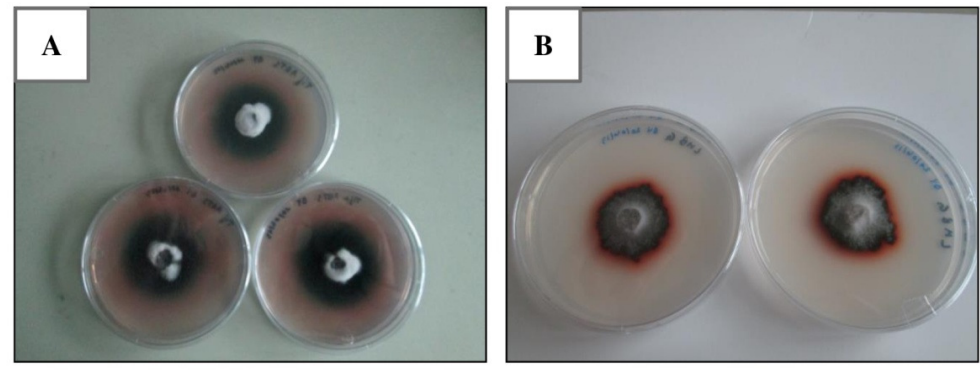

Figure 1: ABTS (A) and guaiacol (B) oxidation by mycelial culture of Bjerkandera adusta BRFM1916

Fungi that possess ligninolytic ability are capable of degrading screening reagents with a structure similar to that of lignin, such as ABTS and guaiacol. This work revealed that the strain showed a green zone on the solid media containing ABTS. However, the absence of extracellular ABTS-oxidizing activity does not necessarily imply the lack of capacity to produce these oxidative enzymes, but could reflect possible inhibition of their expression, as the oxidative enzyme system is not homogeneous and its production and properties depend on the conditions and culture media. Thus, it has been reported earlier that Lentinus squarrosulus gave a positive reaction immediately after inoculation, forming a dark green zone around the mycelial bit, while Bjerkandera adusta showed a very light green colour after 5 days of inoculation. ${ }^{25}$

Guaiacol oxidation is one of the most convenient qualitative assays for lignin modifying enzymes among fungi. Mtui and Masalu ${ }^{26}$ demonstrated guaiacol oxidation by a marine fungal isolate Laetiporus sulphureus after 7 days of incubation. The ability of fungus enzymes to degrade an aromatic model compound implies that the same enzymes could be also used in the removal of aromatic pollutants from industrial effluents. The degrading ability of basidiomycetes fungi is thought to be due to the action of their extracellular oxidative enzymes. ${ }^{27,28}$ 


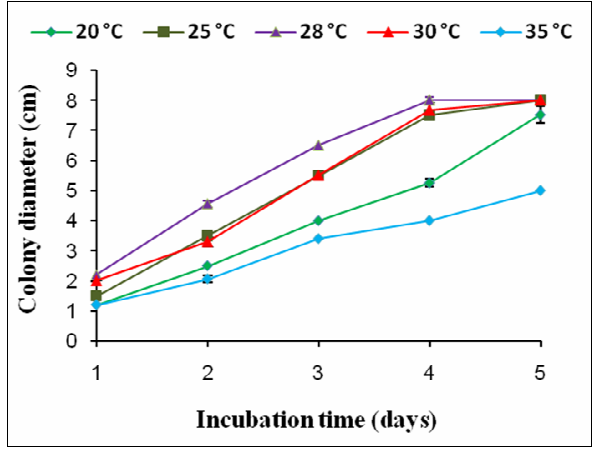

Figure 2: Effect of temperature on growth of Bjerkandera adusta BRFM1916

\section{Temperature effect}

The effect of temperature on mycelial growth is illustrated in Figure 2, which shows a variability of fungal growth at different temperatures depending on the incubation time. In general, mycelial growth increases between $20^{\circ} \mathrm{C}$ and $28{ }^{\circ} \mathrm{C}$, and then decreases during the incubation time. Maximum growth $(8.00 \pm 0.00$ $\mathrm{cm})$ was achieved on the $4^{\text {th }}$ day at $28{ }^{\circ} \mathrm{C}$. From the $3^{\text {rd }}$ day of culture, the growth was not significantly $\quad(p>0.05)$ affected by the temperatures of $25{ }^{\circ} \mathrm{C}$ and $30{ }^{\circ} \mathrm{C}$, and reached a maximum on the $5^{\text {th }}$ day. Furthermore, a significantly weak growth $(p<0.05)$ (except for day 1) was observed with at temperatures of 20 ${ }^{\circ} \mathrm{C}$ and $35^{\circ} \mathrm{C}$. Whatever the temperatures tested in this study, the growth increased significantly $(p<0.05)$ with the incubation time.

Temperature is one of the most important factors for the growth of fungi, because it controls the rates of metabolic reactions, affects enzymatic activity and vitamin synthesis, and may accelerate or inhibit fungus growth. ${ }^{29}$ The temperature range at which most organisms develop is between 0 and $40{ }^{\circ} \mathrm{C} .{ }^{30}$ However, higher temperatures denature the metabolic enzymes of microorganisms, leading to inhibition of growth and enzyme formation. ${ }^{31}$ Our result agrees with those of other researchers, who reported that the optimal growing temperature for Bjerkandera adusta was $28^{\circ} \mathrm{C}^{32}$ Some authors have found the optimum temperature for the growth of basidiomycetes to be between 20 to $30{ }^{\circ} \mathrm{C} .{ }^{33}$ Most white rot fungi are mesophiles and their optimal culture temperature varies from 27 to $30{ }^{\circ} \mathrm{C} .{ }^{34}$ The optimal growth temperature for Trametes versicolor and Bjerkandera sp. approaches 30 ${ }^{\circ} \mathrm{C} .{ }^{35,36}$ Otherwise, the temperatures indicated for

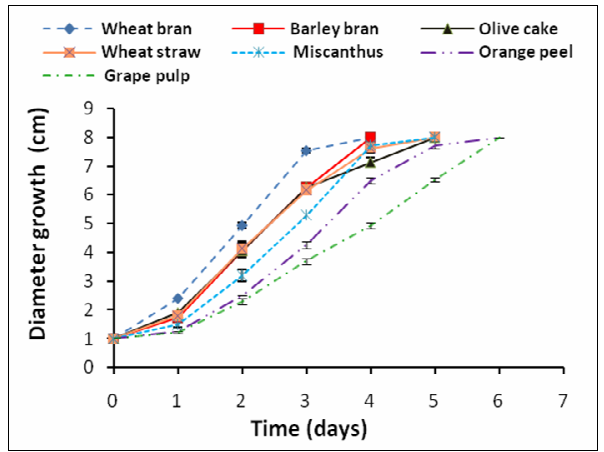

Figure 3: Growth of Bjerkandera adusta BRFM1916 in Petri dishes with lignocellulosic substrates as carbon source

some white-rot fungi, such as Pycnoporus sanguineus and Perreniporia tephropora, were 35 ${ }^{\circ} \mathrm{C}$, and from $30{ }^{\circ} \mathrm{C}$ to $35{ }^{\circ} \mathrm{C}$, respectively. ${ }^{37}$ However, the optimum growth temperature can vary with the species. Thus, an earlier study reported optimum growth from $20^{\circ} \mathrm{C}$ to $30^{\circ} \mathrm{C}$ for Agaricus bioturquis, and from $22{ }^{\circ} \mathrm{C}$ to $25^{\circ} \mathrm{C}$ for Agaricus brasiliensis. ${ }^{38}$ The wide range of variation in the temperature requirement can be attributed to the ecological diversity of fungi. For Granoderma lucidum, the temperature range from $30{ }^{\circ} \mathrm{C}$ to $35{ }^{\circ} \mathrm{C}$ has been reported by Veena and Pandey, ${ }^{39}$ while the range from $25^{\circ} \mathrm{C}$ to $35^{\circ} \mathrm{C}$ has been also found suitable for its growth. ${ }^{40}$ The optimum temperature for Bjerkandera adusta BRFM1916 $\left(28{ }^{\circ} \mathrm{C}\right)$ has an advantage for industrial application, because higher temperature implies more expenses to control moisture and $\mathrm{CO}_{2}$ levels for fungus cultivation. ${ }^{41}$ Moreover, the slow mycelial growth below $25{ }^{\circ} \mathrm{C}$ may be sourced from the reducing metabolic activities of the fungus that allow the absorption of essential nutrients needed for growth. In addition, the slow growth of the selected strain at $35{ }^{\circ} \mathrm{C}$ can be related to possible denaturation of important enzymes, which catalyze fungal metabolic processes.

\section{Effect of agricultural residues on $B$. adusta BRFM1916 growth}

Figure 3 shows variability in the growth of the strain on the tested by-products over time. Wheat bran gave better mycelial growth. During the first three days of culture, mycelium growth on barley bran was significantly similar $(p>0.05)$ to that observed on straw and olive cake. However, on the $4^{\text {th }}$ day of cultivation, the strain reached a maximum of growth at the same time as on wheat 
bran. In addition, during the first two days of culture, fungal growth on grape pulps and orange peels was significantly $(p<0.05)$ slow. Regardless of the substrate, the growth of the strain increased significantly $(p<0.05)$ with incubation time. All these data indicate differential utilization of the various materials by the fungi.

All by-products used in this study have a significant effect $(p<0.05)$ on the growth rate of Bjerkandera adusta BRFM1916 (Table 1).
Indeed, the maximum growth rate of about 2.08 $\mathrm{cm}$ day $^{-1} \pm 0.05$ was observed on wheat bran, followed by barley bran with a significant decrease $(p<0.05)$ of $6.73 \%$. Compared with wheat bran, a significant decrease $(p<0.05)$ of 16.82 was recorded in miscanthus medium, and ranged from 22.11 to $29.32 \%$ on straw, olive cake and orange peels. The lowest growth rate was observed on grape pulp $\left(1.35 \pm 0.02 \mathrm{~cm} \mathrm{day}^{-1}\right)$, with a significant decrease $(p<0.05)$ of $35.09 \%$.

Table 1

Growth rate of Bjerkandera adusta BRFM1916 on different substrates

\begin{tabular}{lc}
\hline Substrate & Growth rate $\left(\mathrm{cm} \mathrm{day}^{-1}\right)$ \\
\hline Wheat bran & $2.08 \pm 0.05$ \\
Grape pulp & $1.35 \pm 0.02$ \\
Miscanthus & $1.73 \pm 0.01$ \\
Orange peels & $1.47 \pm 0.01$ \\
Olive cake & $1.56 \pm 0.08$ \\
Barley bran & $1.94 \pm 0.01$ \\
Wheat straw & $1.62 \pm 0.06$ \\
\hline
\end{tabular}

Mean values ( \pm standard error)

An appropriate approach in fermentation technology development is to utilize the potential of lignocellulosic wastes, some of which may contain significant concentrations of soluble carbohydrates and inducers, ensuring an abundant growth of fungi and efficient production of ligninolytic enzymes. ${ }^{42-45}$ However, variations in biomass composition are typical, considering the types of biomass under investigation. In fact, the hemicelluloses of wheat straw and miscanthus are glucuronoarabinoxylans and $\beta(1,3)-\beta(1,4)$ glucans. ${ }^{46,47}$ On the other hand, for softwoods, the hemicellulosic fraction is represented by galactoglucomannans with $20 \%$ arabinoglucuronone weight.

Lignin is an amorphous heteropolymer, consisting of three different phenyl propane units ( $p$-coumaryl, coniferyl and sinapyl alcohol), which produce, respectively, $p$-hydroxyphenyl, guaiacyl, and syringyl residues when incorporated into the lignin polymer. Lignin in hardwoods is composed mainly of guaiacyl and syringyl units, while in softwoods guaiacyl units predominate. ${ }^{48}$ Also, the lignin-sugars complex of herbaceous plants has a different lignin structure from that found in wood materials and contains ferulic bonds, which link it to sugars (arabinoxylans) via ferulic acid ester bonds. On the other hand, herbaceous biomasses generally have higher unit ratios of $p$-hydroxyphenyl. For example, miscanthus generally contains more $p$ - hydroxyphenyl units (4 to 15\%) than dicotyledons. ${ }^{46} \quad$ Furthermore, previous observations reported that the variability in the strain growth depends on the tested substrate. Some research has indicated that herbaceous biomass possesses higher ash amounts than woody biomass. ${ }^{49,50}$ Wheat and barley brans are rich in soluble fiber. Hemicelluloses are, after starch, the dominant constituent of wheat bran (19\% DM). Conversely, the cellulose fraction is the lowest (11\%), and the lignin fraction is poorly represented $(3 \%){ }^{51}$ Wheat straw cellulose is the major component of straw (36\%), followed by hemicelluloses $(31 \%)$ and lignin (7\%). The lignin proportion is relatively higher than that in wheat bran. ${ }^{6}$ Oil cakes are ideally suited nutrient supports in SSF, rendering both carbon and nitrogen sources, and have been reported to be good substrates for enzyme production using fungal species. Olive cake has low crude protein and high crude fiber content. A large protein proportion (80-90\%) is linked to the lignocelluloses fraction. ${ }^{52}$ Regarding miscanthus, its lignin content is higher than in wheat straw. ${ }^{53}$ Moreover, the glucose content is very high in miscanthus, compared to straw $(47.51 \%$ $\mathrm{DM} / 40.98 \% \mathrm{DM}$, respectively). In addition, orange peels are an excellent carbohydrate source and are low in protein. Grape pulps contain the principal elements for fungal growth, such as fermentable sugars (glucose and fructose), 
organic acids, nitrogenous materials and pigments. They are characterized by the cellulose content of $27.96 \%$ DM, and relatively high lignin content $(18.48 \% \mathrm{DM}) .{ }^{54}$ As it was demonstrated that cellulose and hemicelluloses are the main carbon- and energy- sources for wood-rotting basidiomycetes, we can deduce the key-role played by hydrolytic enzymes in regular nutrients supply for fungal growth.

\section{Effect of by-products on ligninocellulose- degrading enzymes production}

The analysis of lignocellulolytic enzyme activities (CMCase, $\beta$ - Glu, MnP, Lac, LiP), produced by the fungal strain during growth, showed a variation of enzyme production based on the agricultural residue used as substrate. Laccase and lignin peroxidase activities were not detected (Fig. 4). Maximum CMCase activity $\left(690 \pm 0.066 \mathrm{UL}^{-1}\right)$ was observed in the culture supernatant from wheat bran. However, this activity varies with the by-product used. The order of the lignocellulosic substrates for the CMCase activity ( $\mathrm{UL}^{-1}$ ) is the following: wheat bran $(690)>$ miscanthus $(212)>$ orange peels $(157)>$ olive cake $(140)>$ wheat straw $(138)>$ barley bran (94) $>$ grape pulp (28), with a difference of 24.6 times between the wheat bran and grape pulps. The analysis of variance (ANOVA) showed that the CMCase activity was not significantly $(p>0.05)$ different among the culture supernatants from the olive cake, wheat straw and barley bran. $\beta$-Glu activity $\left(\mathrm{UL}^{-1}\right)$ also showed variation as a function of the by-products used according to the following order: orange peels $(253)>$ wheat bran $(160)>$ miscanthus $(66)$ $>$ grape pulp $(45)>$ wheat straw $(32)>$ olive cake
(27) > barley bran (12), with a difference of 21 times between the extreme values. The lowest $\beta$ Glu activity, detected in the culture supernatant from barley bran, did not significantly $(p>0.05)$ differ from those obtained in the olive cake supernatant. The fungus showed varied MnP activities according to the concerned lignocellulosic substrate. Wheat bran provided the highest activity $\left(\mathrm{UL}^{-1}\right)(449.21 \pm 3.44)$, followed by barley bran $(263.07 \pm 2.10)$, olive cake $(232.47$ $\pm 3.57)$, wheat straw (121.36 \pm 1.44$)$, grape pulp $(116.02 \pm 3.15)$, miscanthus $(82.75 \pm 1.31)$, and orange peels $(33.81 \pm 5.46)$, with a difference of 13.3 times between wheat bran and orange peel. The MnP activities on the grape pulps and wheat straw did not differ significantly $(p>0.05)$.

The rate of mycelial growth varied among the substrates under investigation. However, this growth variation does not appear to correlate with the different enzymatic induction. Indeed, orange peels were among the substrates that produced the slowest growth rates. However, $\beta$-Glu activity in this substrate is the highest. In addition, although barley bran is the substrate that allowed good fungal growth, low cellulase activity was found on it, compared to the other substrates. Our results are similar to those reported by Quiroz-Castaneda et al. $^{18}$ using cedar sawdust as a substrate for cellulases production by $B$. adusta. Furthermore, in comparison with hydrolases, barley bran, olive cake and grape pulps induced MnP synthesis. Barley bran has an elevated $\mathrm{MnP}$ activity $\left(\mathrm{UL}^{-1}\right)$ $(263.07 \pm 2.10)$ against CMCase activity (94.67 \pm 8.61). The strain produced $\left(\mathrm{UL}^{-1}\right) 116.02 \pm 3.15$ (MnP), $28.96 \pm 7.98$ (CMCase) and $45.45 \pm 5.73$ $(\beta-\mathrm{Glu})$ on grape pulp.

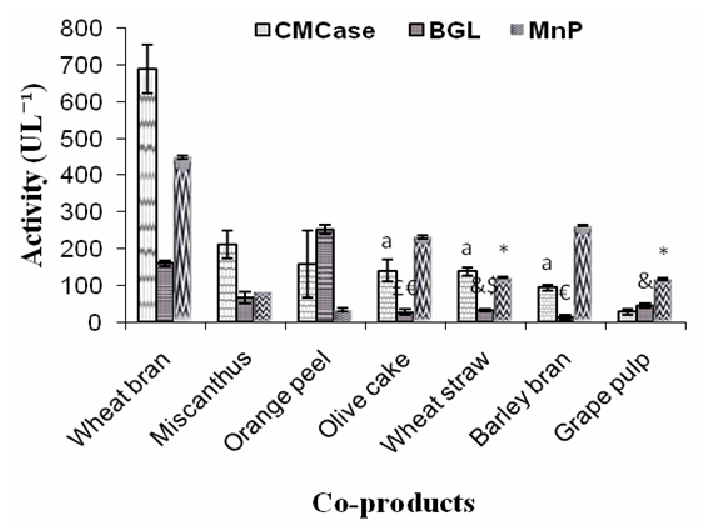

Figure 4: Lignocellulolytic enzymes production by Bjerkandera adusta BRFM1916 on different agricultural residues used as substrates 
Several studies reported that wheat bran is an excellent substrate to increase yield production of multi-enzyme complexes of carbohydrolases and oxidases. ${ }^{55,47}$ Additionally, significant differences in lignocellulolytic enzyme yields were observed upon variation of the growth substrates. The ratio of individual hydrolytic and oxidative enzymes in liquid culture and even the proportion of isoenzymes significantly depended on the type of the lignocellulosic substrate. ${ }^{56}$ This may due to the difference in substrate composition. Indeed, high cellulose concentration can raise cellulase activity. ${ }^{18}$ In addition, the elevated MnP activity on some tested by-products, such as wheat bran, olive cake, barley bran, wheat straw and grape pulps, could be explained by the presence in these substrates of easily extractable and available compounds, as well as free sugars, organic acids and soluble aromatic compounds, thus providing abundant fungal growth and inducing biosynthesis of ligninolytic enzymes. ${ }^{57}$ The inductive capability of rice bran to produce laccase may be related to its phenolic compounds, such as ferulic and vannilic acids, known by their capability to induce laccase production by whiterot fungi. ${ }^{58}$

Regarding LiP and Lac, these enzymes were not detected in our culture conditions. However, this does not mean that the strain does not produce them. Lac activity was observed in wheat bran on SSF, but it was not detected on other lignocellulosic residues, such as wheat straw, miscanthus, olive cake, grape pulps, miscanthus/olive cake, wheat straw/olive cake and orange peels (data not shown). Some reports indicate that the culture method is an important factor for enzyme biosynthesis in fungi. So, various plant raw materials have been used successfully for lignocellulolytic enzyme production in submerged (SF) and solid-state (SSF) fermentation. ${ }^{44,59}$ Nevertheless, in SSF, the fungi grow under conditions close to their natural habitats, which explains their capability to produce enzymes, as compared to submerged cultures. ${ }^{60}$

Our results suggest that the nature of the lignocellulosic substrate can determine the types and the quantity of ligninolytic enzymes produced by Bjerkandera adusta. However, it is not inconceivable that part of the secreted enzyme proteins may be differently immobilized on different types of lignocellulosic substrates and therefore it is impossible to reliably assess the effects of these substrates on the enzyme production. ${ }^{18}$

\section{CONCLUSION}

The present study investigated the effect of several agricultural residues (wheat bran, wheat straw, olive cake, miscanthus, grape pulp, barley bran, and orange peels) used as low-cost substrates, on the fungal growth and the production of ligninocellulolytic enzymes by Bjerkandera adusta BRFM 1916.

The experimental work revealed that fungal growth increased between $20{ }^{\circ} \mathrm{C}$ and $28{ }^{\circ} \mathrm{C}$, and then decreased during the incubation time. The results indicated differential utilization of the various agro-industrial by-products by $B$. adusta BRFM1916. Wheat bran allowed better mycelial growth, followed by barley bran.

The production of lignocellulolytic enzymes using agricultural residues or wastes is one of the most efficient biological ways by which these byproducts can be recycled, through a value-adding process, converting them into useful chemicals or fuels. Although various agro-industrial residues have been used for the production of ligninolytic enzymes by the genus Bjerkandera, according to our literature review, among the substrates tested, olive cake, grape pulp, barley bran, miscanthus and orange peels have never or rarely been exploited by researchers. The results obtained in this study for the different by-products indicate that the enzymes production varies according to the lignocellulosic substrate. The maximum CMCase activity was observed in the culture supernatant from wheat bran, followed by miscanthus, orange peels, olive cake, wheat straw, barley bran, and grape pulp. High $\beta$-Glu activity was recorded for orange peels $\left(253 \mathrm{UL}^{-1}\right)$, followed by wheat bran $\left(160 \mathrm{UL}^{-1}\right)$. The lowest activity was obtained on barley bran $\left(12 \mathrm{UL}^{-1}\right)$, with a difference of 21 times between the extreme values. For the $\mathrm{MnP}$, wheat bran provided the highest activity (449.21 UL $\mathrm{UL}^{-1}$ ), followed by barley bran $\left(263.07 \mathrm{UL}^{-1}\right)$, olive cake $\left(232.47 \mathrm{UL}^{-1}\right)$, wheat straw $\left(121.36 \mathrm{UL}^{-1}\right)$, grape pulp (116.02 $\left.\mathrm{UL}^{-1}\right)$, miscanthus $\left(82.75 \mathrm{UL}^{-1}\right)$, and orange peels $\left(33.81 \mathrm{UL}^{-1}\right)$, with a difference of 13.3 times between wheat bran and orange peel. However, laccase and lignin peroxidase activities were not detected in our conditions. Although the rate of mycelial growth varies among the different growth substrates, this growth variation does not appear to correlate with the different enzymatic induction. 
In addition, the study demonstrated the ligninolytic ability of the enzymes produced by the strain examined under the conditions used, by assessing the ABTS and guaiacol oxidizing activities. The ability of the enzymes produced by Bjerkandera adusta BRFM1916 to degrade aromatic model compounds implies that these enzymes could also be used in bioremediation technologies, for removing aromatic pollutants from industrial effluents.

Based on the obtained results, it can be concluded that the substrates investigated in our study can be valorized for the production of lignocellulolytic enzymes by Bjerkandera adusta under solid state fermentation. Further studies are required to explore these substrates separately and in combination in order to study their effect on the enzyme yield.

\section{REFERENCES}

1 P. Baldrian and J. Šnajdr, in "Soil Enzymology", edited by G. Shukla and A. Varma, Springer, 2011, pp. 167-186, https://doi.org/10.1007/978-3-642-142253_-9

2 S. I. Mussatto, L. F. Ballesteros, S. Martins and J. A. Teixeira, in "Industrial Waste", edited by K. Y. Show and X. Guo, IntechOpen, 2012, pp. 121-140, https://doi.org/10.5772/36310

3 O. Sanchez, R. Sierra and C. J. Alméciga-Díaz, in "Alternative Fuel", edited by M. Manzanera, IntechOpen, 2011, p. 111-154, https://doi.org/10.5772/22381

4 C. Sanchez, Biotechol. Adv., 27, 185 (2009), https://doi.org/10.1016/j.biotechadv.2008.11.001

C. Ayoo, S. Bonti-Ankomah and N. A. Aryee Alberta, in "Byproducts from Agriculture and Fisheries: Adding Value for Food, Feed, Pharma and Fuels", edited by B. K. Simpson, N. A. Aryee Alberta and F. Toldrá, Wiley, 2019, pp. 699-711, https://doi.org/10.1002/9781119383956.ch32

6 K. Niladevi, in "Biotechnology for AgroIndustrial Residues Utilization", edited by P. Singh, N. Nigam and A. Pandey, Springer, 2009, pp. 397414, https://doi.org/10.1007/978-1-4020-9942-7_22

7 R. Ravindran, S. S. Hassan, G. A. Williams and A. K. Jaiswal, Bioengineering, 5, 1 (2018), https://dx.doi.org/10.3390\%2Fbioengineering5040093

8 P. K. Sadh, S. Duhan and J. S. Duhan, Bioresour.

$\begin{array}{llll}\text { Bioprocess., } & 5, & 1 & \text { (2018), }\end{array}$ https://doi.org/10.1186/s40643-017-0187-z

9 T. M. Pasin, P. Z. de Almeida, A. S. de Almeida Scarcella, J. da Conceição Infante and M. L. Teixeira de Moraes Polizeli, in "Biorefinery of Alternative Resources: Targeting Green Fuels and Platform Chemicals", edited by S. Nanda, D.-V. N. Vo and P. K. Sarangi, Springer, 2020, pp. 23-47, https://doi.org/10.1007/978-981-15-1804-1_2
10 E. Birhranly and O. Yesilada, Turk. J. Biol., 37, 450 (2013), https://doi.org/10.3906/biy-1211-25

11 B. S. Sooch, Y. Lugani and R. S. Singh, in "Industrial Biotechnology Plant Systems, Resources and Products", edited by M. Yadav and V. Vikas Kumar, De Gruyter, 2019, pp. 31-50, https://doi.org/10.1515/9783110563337

12 P. Singh-Nee Nigam and A. Pandey, in "Biotechnology for Agro-Industrial Residues Utilization Solid-State Fermentation Technology for Bioconversion of Biomass and Agricultural Residues", edited by P. Singh-Nee Nigam and A. Pandey, Springer, 2009, pp. 197-221, https://doi.org/10.1007/978-1-4020-9942-7_10

13 A. Dhouib, M. Hamza, H. Zouari and T. Mechichi, Afr. J. Biotechnol., 4, $431 \quad$ (2005), https://doi.org/10.1007/s11274-005-5774-z

14 S. B. Pointing, Fungal Divers., 2, 17 (1999)

15 K. T. Steffen, M. Hofrichter and A. Hatakka, Appl. Microbiol. Biotechnol., 54, $819 \quad$ (2000), https://doi.org/10.1007/s002530000473

16 L. K. Okino, K. M. G. Machado, C. Fabric and V. L. R. Bonomi, World J. Microb. Biot., 16, 889 (2000), https://doi.org/10.1023/a:1008983616033

17 G. D. Inglis, A. P. Popp, L. B. Selinger, L. M. Kawchuk, D. A. Gaudet et al., Can. J. Microbiol., 46, 860 (2000), https://doi.org/10.1139/w00-057

18 R. E. Quiroz-Castaneda, N. Perez-Mejia, C. Martinez-Anaya, L. Acosta-Urdapilleta and J. FolchMallol, Biodegradation, 22, 565(2011), https://doi.org/10.1007/s10532-010-9428-y

19 T. K. Ghosse, Pure Appl. Chem., 59, 257 (1987), https://doi.org/10.1351/pac198759020257

20 G. L. Miller, Anal. Chem., 31, 426 (1959), https://doi.org/10.1021/ac60147a030

21 B. Norkrans, Physiol. Plant., 10, 198 (1957), https://doi.org/10.1111/j.1399-3054.1957.tb07621.x

22 A. Lomascolo, J. L. Cayol, M. Roche, L. Guo, J. L. Robert et al., Mycol. Res., 106, 1193 (2002), https://doi.org/10.1017/s0953756202006494

23 A. Paszczynski, V. B. Huynh and R. Crawford, Arch. Biochem. Biophys., 244, 750 (1986), https://doi.org/10.1016/0003-9861(86)90644-2

24 M. Tien and T. K. Kirk, Proc. Natl. Acad. Sci. U.S.A., $\quad \mathbf{8 1}, \quad 2280$ https://doi.org/10.1073/pnas.81.8.2280

25 A. Tripathy, R. C. Upadhyay and S. Singh, Indian J. $\quad$ Microbiol., $\quad \mathbf{5 2}, \quad 381 \quad$ (2012), https://doi.org/10.1007/s12088-011-0232-0

26 G. Mtui and R. Masalu, Sci. Res. Essays, 3, 154 (2008), https://doi.org/10.5897/SRE.9000495

27 K. G. Wunch, T. Feibelman and J. W. Bennett, Appl. Microbiol. Biotechnol., 47, 620 (1997), https://doi.org/10.1007/s002530050984

28 P. C. George, K. Susan and T. M. Brouse, Compost. Sci. Util., 8, 6 (2000), https://doi.org/10.1080/1065657x.2000.10701743

${ }_{29}^{2}$ P. G. Miles and S. T. Chang, "Mushroom Biology: Concise Basics and Current Developments", 
Singapore, World Scientific, 1997, 216 p., http://dx.doi.org/10.1142/9789812839794

30 J. Gillooly, E. L. Charnov, G. B. West, B. M. Savage and J. H. Brown, Nature, 417, 70 (2002), https://doi.org/10.1038/417070a

31 M. K. Tripathi, A. S. Mishra, A. K. Misra, S. Vaithiyanathan, R. Prasad et al., Lett. Appl. Microbiol., 46, 364 (2008), https://doi.org/10.1111/j.1472765x.2008.02320.x

32 R. Quiroz-Castaneda, E. Balcazar-Lopez, E. Dantan-Gonzalez, A. Martinez, J. L. Folch-Mallol et al., Electron. J. Biotechnol., 12, 1 (2009), https://doi.org/10.2225/vol12-issue4-fulltext-3

33 B. Kibar and A. Peksen, Zemdirbyste, 98, 409 (2011)

34 A. Pavko, in "Waste Water - Treatment and Reutilization”, edited by F. S. García Einschlag, IntechOpen, 2011, pp. 65-88, https://doi.org/10.5772/16120

35 M. A. Pickard, R. Roman, R. Tinoco and R. Vazquez-Duhalt, Appl. Environ. Microbiol., 65, 3805 (1999), https://doi.org/10.1128/aem.65.9.38053809.1999

36 J. Swamy and J. A. Ramsay, Enzyme Microb. Technol., $\quad \mathbf{2 4}, \quad 130 \quad$ (1999), https://doi.org/10.1016/S0141-0229(98)00105-7

37 C. Atteke, S. Mounguengui, I. Brama, G. Ella and B. Mbatchi, Int. J. Adv. Res., 2, 165 (2014)

38 T. H. Quimio, S. T. Chang and D. J. Royse, FAO Plant Production and Protection Paper 106, FAO, 1990, $155 \mathrm{p}$.

39 S. S. Veena and M. Pandey, J. Mycol. Plant Pathol., 36, 434 (2006)

40 P. Kapoor and B. M. Sharma, Int. J. Sci., Environ. Technol., 3, 1515 (2014)

41 N. B. Colauto, P. M. Aizono, L. R. M. Carvalho, L. D. Paccola-Meirelles and G. A. Linde, Semin. Cienc. Agrar., 29, 307 (2008), https://doi.org/10.5433/16790359.2008v29n2p307

42 A. N. Kapich, B. A. Prior, A. Botha, S. Galkin, T. Lundell et al., Enzyme Microb. Technol., 34, 187 (2004), https://doi.org/10.1016/j.enzmictec.2003.10.004

43 E. Rosales, S. Rodriguez Couto and M. A. Sanroman, J. Food Eng., 66, 419 (2005), https://doi.org/10.1016/j.jfoodeng.2004.04.010
44 E. Kachlishvili, M. J. Penninckx, N. Tsiklauri and V. Elisashvili, World J. Microb. Biot., 22, 391 (2006), https://doi.org/10.1007/s11274-005-9046-8

45 G. Songulashvili, V. Elisashvili, S. P. Wasser, E. Nevo and Y. Hadar, Enzyme Microb. Technol., 41, 57 (2007), https://doi.org/10.1016/j.enzmictec.2006.11.024

46 I. Moller, I. Sørensen, A. J. Bernal, C. Blaukopf and K. Lee et al., Plant J., 50, 1118 (2007), https://doi.org/10.1111/j.1365-313X.2007.03114.X

47 Y. Peng and S. Wu, J. Anal. Appl. Pyrol., 88, 134 (2010), https://doi.org/10.1016/j.jaap.2010.03.006

${ }_{48}$ P. Sannigrahi and Y. Pu, Curr. Opin. Environ. $\begin{array}{llll}\text { Sust., } & \mathbf{2}, & 383 & \text { (2010), }\end{array}$ https://doi.org/10.1016/j.cosust.2010.09.004

49 A. M. Azeez, D. Meier, J. Odermatt and T. Willner, Energ. Fuel., 24, 2078 (2010), https://doi.org/10.1021/ef9012856

50 C. Torri, A. Adamiano, D. Fabbri, C. Lindfors, A. Monti et al., J. Anal. Appl. Pyrol., 88, 175 (2010), https://doi.org/10.1016/j.jaap.2010.04.003

51 M. Bataillon, P. Mathaly, A. Nunes Cardinali and F. Duchiron, Ind. Crop. Prod., 8, 37 (1998), https://doi.org/10.1016/s0926-6690(97)10002-4

52 R. A. Swick, ASA Technical Bull., 21, 1 (1999)

53 E. Butler, G. Devlin, D. Meier and K. Mcdonnell, Bioresour. Thechnol., 131, $202 \quad$ (2013), https://doi.org/10.1016/j.biortech.2012.12.013

54 G. M. Chiericato and M. Rioni, Zootec. Nutr. Anim., 9, 89 (1983)

55 D. F. Souza, G. K. Tychanowicz, C. G. M. Souza and R. M. Perelta, J. Basic Microbiol., 46, 126 (2006), https://doi.org/10.1002/jobm.200510014

56 D. Moldes, M. Lorenzo and M. A. Sanromán, Biotechnol. Lett., 26, $327 \quad$ (2004), https://doi.org/10.1023/b:bile.0000015452.40213.bf

57 F. Patrick, G. Mtui, A. M. Mshandete and A. Kivaisi, Afr. J. Biotechnol., 10, 10166 (2011), https://doi.org/10.5897/AJB11.863

58 J. M. Bollag and A. Leonowicz, Appl. Environ. Microbiol., 48, 849 (1984), https://doi.org/10.1128/aem.48.4.849-854.1984 59 V. Elisashvili, E. Kachlishvili and M. Penninck, $J$. Ind. Microbiol. Biot., 35, 1531 (2008), https://doi.org/10.1007/s10295-008-0454-2

60 A. Pandey, P. Selvakumar, C. R. Soccol and P. Singh-Nee Nigam, Curr. Sci., 77, 149 (1999) 